\title{
A Novel Protection Scheme to Prevent Unnecessary Outages of Generating Units During Power System Disturbances
}

\author{
${ }^{1}$ Mohamed K. Atalah, ${ }^{2}$ Hassan Mahmoud and ${ }^{3}$ Zaki Mattar \\ ${ }^{1}$ Cairo Electricity Production Company, Cairo, Egypt \\ ${ }^{2}$ Egyptian Electricity Holding Company, Cairo, Egypt \\ ${ }^{3}$ Faculty of Engineering, AL-Azhar University, Cairo, Egypt
}

\begin{abstract}
This study proposes a communication-based protection scheme that prevents the unnecessary generator tripping by the generator distance phase backup protection (Relay 21) during common system disturbances, namely high impedance faults. This could maintain the local generator connected to fulfill the system requirements during and after such events. This research highlights the need for using an IEC 61850-based protection scheme to coordinate the tripping action between Relay 21 and transmission line distance protection during power system disturbances. This scheme can be simply implemented using the current technologies of the existing protection relays. The scheme is modeled and simulated using the Xelas IEC 61850 Simulator and MATLABß Software. The simulated system is configured according to the typical parameters of the Egyptian grid. Satisfactory results have been obtained proving the scheme validity.
\end{abstract}

Key words: Distance protection, generator distance phase backup protection, GOOSE, IEC 61850, protection scheme, power system disturbances, unnecessary generator tripping

\section{INTRODUCTION}

Transmission lines are susceptible to fault conditions due to exposition to switching and environmental conditions (Gaur et al., 2015). High Impedance Faults (HIFs) in transmission system occur when a line falls on high impedance surfaces such as sand, asphalt road, grass or cement. They are also caused by tree limbs that come into contact with the transmission line, a construction crane or fire (Mamishev et al., 1996; IEEE PSRC, 2011). These kinds of faults create problems for many relaying schemes in the network.

Recent outages of generating units during power system disturbances have highlighted the need for an IEC 61850-based protection scheme to coordinate the role of tripping action between Relay 21 and transmission line distance protection $\left(\mathrm{R}_{\mathrm{TL}}\right)$ in order to avoid the unnecessary outages of generating units during such events. The impact of system disturbances on the performance of generator protection has been reported in (Patel et al., 2004; Tziouvaras, 2007). The proposal for increasing the time delay and decreasing the impedance reach settings of Relay 21 in order to allow the generator to provide the needed support during system disturbances has been studied and reported by Elsamahy et al. (2012).

The proposed scheme coordinates between the Relay 21 and $\mathrm{R}_{\mathrm{TL}}$ in order to arrange the role of tripping action during Transmission Line HIFs (TL HIFs), this arrangement would maintain the generator connected to supply other loads such as tie transformers and other lines. Moreover, the proposed scheme provides smart IEC 61850 communications between Relay 21 and $\mathrm{R}_{\mathrm{T}}$ located in the local high voltage switchyard. These communications can be achieved through the existing protection relays that support IEC 61850 standard. The performance of Relay 21 and $\mathrm{R}_{\mathrm{TL}}$ after applying the proposed scheme is studied in this study during T.L HIFs. The contributions of this study are listed as follows:

- It demonstrates the problem caused by the unnecessary operation of Relay 21 during T.L HIFs which causes unnecessary outages of generating units

- It is believed to be the first proposal of an IEC 61850 based protection scheme to provide a solution for the unnecessary outages of the generators by Relay 21 during T.L HIFs

Generator distance phase backup protection: Relay 21 is designed to protect the generator against phase faults outside its protection zone, if these faults are not cleared by other relays after an appropriate time delay (Elsamahy et al., 2012). A mho type characteristic is commonly utilized with one or two protection zones. If only one protection zone is utilized, the setting is determined based on the criterion of zone 2 (which is the

Corresponding Author: Mohamed K. Atalah, Cairo Electricity Production Company, Cairo, Egypt 
criterion considered in this research) (Mozina et al., 2007). The primary purpose of Relay 21 is to measure the impedance (positive sequence) from the relay point to the fault location where the relay reach starts from the relay point and extends to the longest transmission line length which is out of the power plant switchyard (Mozina et al., 2007; IEEE PSRC, 2011). Relay 21 is designed to be set within the generator capability with a suitable margin for stable power swings and overload. Thus, the impedance reach of Relay 21 is set at the smallest of the following criteria (Mozina, 2006):

- The $120 \%$ of the longest line length with considering in-feeds

- The $50-67 \%$ of the generator load impedance (Zload) at the Rated Power Factor Angle (RPFA). "This provides a margin of $150-200 \%$ over the generator full load"

- The $80-90 \%$ of the Zload "at the Maximum relay Torque Angle setting (MTA) (typically $85^{\circ}$ )"

The impedance reach setting of Relay 21 is set as per the second criterion (which is considered in this research) to provide thermal backup protection for the generator against line faults which are not cleared by $\mathrm{R}_{\mathrm{TL}}$ (IEC., 2010). Furthermore, Relay 21 must be coordinated with the backup zone of $\mathrm{R}_{\mathrm{TL}}$ to achieve selectivity Mozina et al., 2007. Thus, the time delay setting of Relay 21 must be set longer than the backup Zone $(\mathrm{Z} 3)$ of $\mathrm{R}_{\mathrm{TL}}(0.8-1 \mathrm{sec})$ with a suitable margin (Elsamahy et al., 2012). Thus, the time delay setting considered for Relay 21 Zone 2 (Z2) in this study is $1.1 \mathrm{sec}$ (which is the time delay setting considered in most of Egyptian generating units).

\section{Generator Capability Curve (GCC)}

Limits of GCC: The GCC establishes the operating limits of the generator active and reactive power. It is combined of three curves, these curves represent the limits of the stator winding, stator end iron and rotor winding as shown in Fig. 1 a (Mozina, 2006). The limits of stator and rotor windings (long-term conditions) are relative to the current carrying capability of the stator and rotor windings, respectively. The limit of stator end iron is a short time condition, it is caused by a decreasing in the field current to the limit where high excitation is fed from the system into the generator (IEEE PSRC, 2011).

Conversion of P-Q to R-X diagram: The characteristics of GCC are plotted on a P-Q diagram (MW-MVAR) as shown in Fig. 1 while the characteristics of Relay 21 are displayed on the R-X diagram (resistance-reactance). Thus, to coordinate GCC characteristics with Relay 21 characteristics, it is needed to convert GCC characteristics to $\mathrm{R}-\mathrm{X}$ diagram as shown in Fig. 1b. The transformation ratio $(\mathrm{Rc} / \mathrm{Rv})$ converts the primary values to secondary values that are used by the relay and $(\mathrm{kV})$ is the generator rated voltage (Mozina et al., 2007; IEEE PSRC, 2011).

Transmission line distance protection Relay $\left(R_{\mathrm{TL}}\right)$ : Characteristics of $\mathrm{R}_{\mathrm{TL}}: \mathrm{R}_{\mathrm{TL}}$ is typically used to protect the transmission line against faults. $R_{T L}$ measures the fault impedance using the measured signals by the current and voltage transformers at the same location and compares it with its setting values to decide which zone contains the fault (Ziegler, 2011). Many different types of characteristics are used for $\mathrm{R}_{\mathrm{TL}}$ such as the lens, mho, quadrilateral and tomato. These different characteristics allow for different applications (Rincon and Perez, 2012). These characteristics show the impedance locus on the $\mathrm{R}-\mathrm{X}$ diagram and specify the relay response in case of fault occurrence. Typically, three zones are defined for (a)

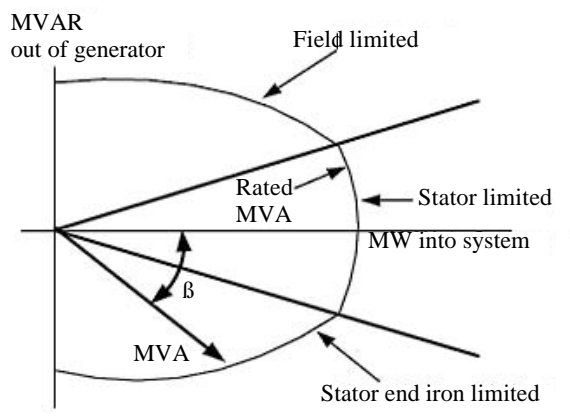

MVAR

into generator (b)

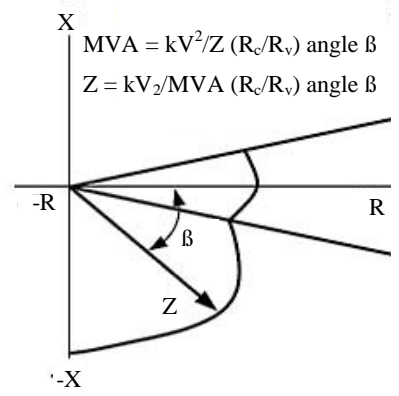

Fig. 1: Conversion of GCC from P-Q to R-X diagram: a) GCC on the P-Q diagram and b) GCC on the R-X diagram (IEEE PSRC, 2011) 
distance relays in order to protect the line and give backup protection for the next sections (Rani and Sridevi, 2016).

Setting of $\mathbf{R}_{\mathrm{TL}}$ : The setting of $\mathrm{R}_{\mathrm{TL}}$ is accomplished correctly by adjusting an instantaneous protection Zone (Z1) and two more time-delayed Zones (Z2 and Z3) (Li et al., 2008). The strategy considered by the Egyptian grid authority in adopting the settings of distance relay is summed up as follows (Gilany et al., 2000): the first protection Zone (Z1) is set to protect $80 \%$ of the line length and operates instantaneously. The second protection Zone (Z2) is set to protect $100 \%$ of the line length plus a safety margin, normally $40 \%$ of the next shortest line length. The time delay of this zone is adjusted at $500 \mathrm{msec}$. The third protection Zone (Z3) is set to protect $100 \%$ of protected line length plus $100 \%$ of the next shortest line section plus a safety margin which is normally $20 \%$ of the second shortest line length following the protected line. The time delay of this zone is adjusted at $1 \mathrm{sec}$ in order to give the needed coordination with the other relays at the next line sections.

IEC 61850 GOOSE protocol: The IEC 61850 standard for substations enables the integration of all control, protection, measurement and monitoring functions. These functions require high speed and reliable communications in the substations. Traditionally, this was achieved using copper wires between the control station and IEDs and between the IEDs in the substation. However, using copper wires for communication creates a very complex network of wires inside the substation. Now, Ethernet-based Local Area Network (LAN) provides better reliability, speed and is easy to maintain (Fernandes et al., 2014).

As a LAN based protocol, Generic Object Oriented Substation Event (GOOSE) is reliable for status and event exchange between IEC 61850 based IEDs either for protection or for control. Some critical control operations (such as interlocking and auto-reclosing signals) and protection related signals (such as trip and blocking) utilize IEC 61850-8-1 based communication service for status and event delivery within real-time control and protection facilities. However, performing real-time delivery GOOSE communications offers time-critical features by using the Ethernet (IEEE 802.3) multicasting paradigm (Fernandes et al., 2014).

IEC 61850 states that the signal of interest (which is "trip" or "block trip" in this study) has to be transmitted continuously on the network by the relevant IED. On the other hand, IED needing this signal has to read it in the proper time. This transmitting IED is called "publisher" while the IED that should get the transmitted information is called "subscriber" (IEC., 2010). The GOOSE message is retransmitted at a steady frequency until the GOOSE data changes. At that time, the original stream stops and a new message is generated immediately at very high frequency. Figure 2 shows the GOOSE conceptual mechanism.

Problem formulation: Due to $\mathrm{HIF}$ s and their related arcing behavior, the impedance seen by $\mathrm{R}_{\mathrm{TL}}$ changes constantly and randomly (Mamishev et al., 1996). As a result, the operation of $\mathrm{R}_{\mathrm{TL}}$ is affected, since, it will locate the fault at a longer distance than its actual location (Gilany et al., 2000 ). Consequently, the backup zone of $R_{T L}$ will be initiated instead of the relevant zone (for example $\mathrm{R}_{\mathrm{TL}}$ will initiate $\mathrm{Z} 3$ and its delay timer $\left(\mathrm{t}_{3}\right)$ for faults located at $\left.\mathrm{Z} 2\right)$. In the meantime, Relay 21 will be also initiated and its timer starts. Since, the time delay of Relay $21 \mathrm{Z} 2$ is very close to that of $R_{T L} Z 3$, there is a probability that Relay 21 $\mathrm{Z} 2$ operates prior to $\mathrm{R}_{\mathrm{TL}} \mathrm{Z3}$ due to realistic mismatches between the two relays. This situation has been recorded

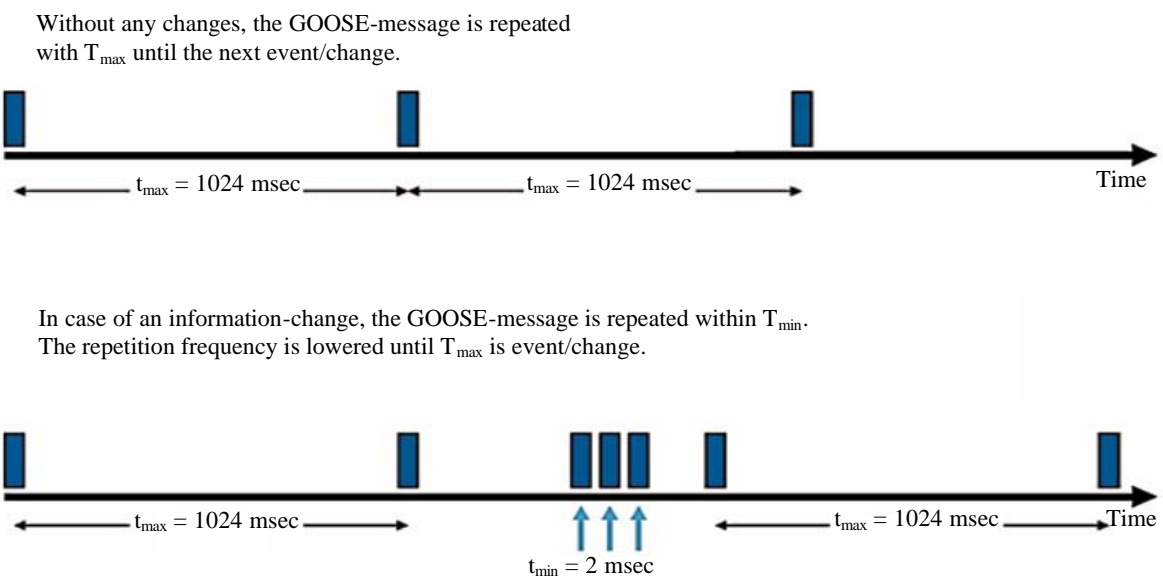

Fig. 2: GOOSE messaging mechanism 
in some actual incidences occurred in the Egyptian grid where Relay 21 happens to trip the generator before $\mathrm{R}_{T L}$ trips the faulted line. This action will affect severely the continuity of power supply to the system and reduce the system reliability in such events.

\section{MATERIALS AND METHODS}

Proposed scheme: An IEC 61850-based protection scheme is introduced to coordinate between Relay 21 and $\mathrm{R}_{\mathrm{TL}}$ through GOOSE communications during T.L HIFs in order to avoid the unnecessary generator tripping by Relay 21 . Therefore, the performance of Relay 21 and $R_{T L}$ is improved during such events without affecting their basic functions. This scheme coordinates the role of tripping action between Relay 21 and $\mathrm{R}_{\mathrm{TL}}$ through GOOSE messages as shown in Fig. 3. Figure 4 shows a flow chart representing the operation of the scheme during T.L HIFs.

System under study: Figure 5 shows the model used in this research to examine the proposed scheme, this model represents an actual part of the Egyptian grid with actual

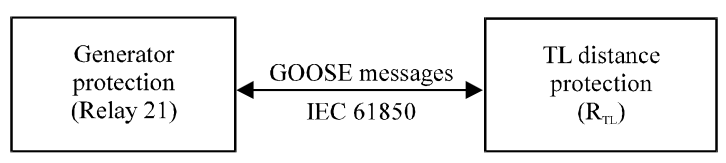

Fig. 3: Coordination between Relay 21 and $R_{T L}$ using GOOSE messages

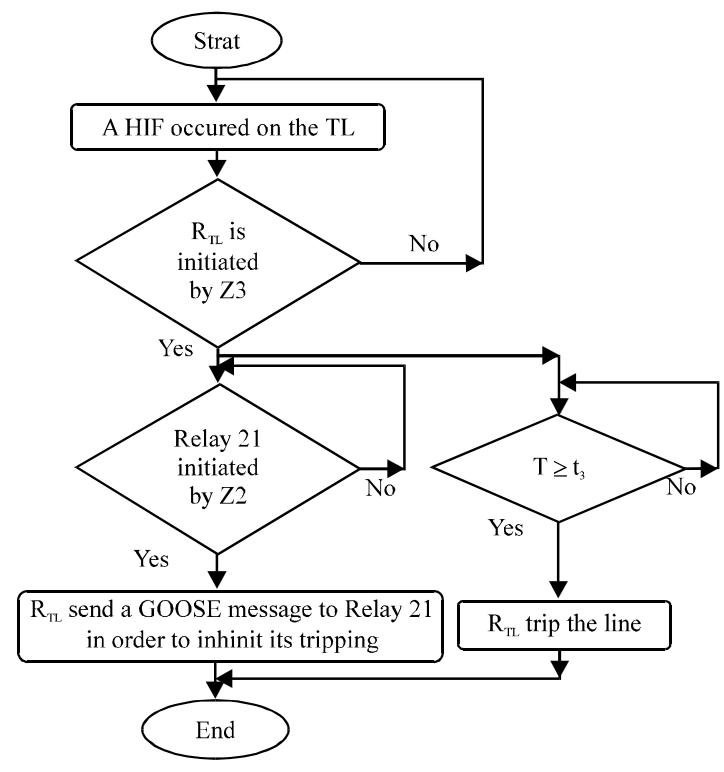

Fig. 4: Operation of the proposed scheme parameter as a case study. It consists of El-Tibin thermal power plant $437 \mathrm{MVA}, 21 \mathrm{kV}$ connected via. a Generator Step-up Transformer (GSUT) 480 MVA to an infinite-bus system through a $140 \mathrm{~km}, 220 \mathrm{kV}$ transmission line. The setting values of Relay $21, \mathrm{R}_{\mathrm{TL}}$ and system data are provided in the Appendix. The simulations of this model have been performed using the Xelas IEC 61850 energy management simulator and MATLAB ${ }^{\circledR}$ Software.

The model shown in Fig. 5 is used for simulation purpose, however, it doesn't restraint the more common case of having more than one generator in the power plant where all are connected to the grid through a number of transmission lines.

Coordination of Relay 21 characteristics and GCC limits: Relay $21 \mathrm{Z} 2$ (Z21) is set at $67 \%$ of (Zload) at $\mathrm{RPFA}=19.95^{\circ}$ which yields $Z 21=17 \Omega$ (impedance reach of Relay 21 at $\mathrm{MTA}=85^{\circ}$ ). Finally, the characteristics of GCC on the P-Q diagram are converted into the R-X diagram and plotted with Relay 21 characteristics as shown in Fig. 6.

Characteristics of $\mathbf{R}_{\mathrm{TL}}$ : The impedance reach of $Z 1$ is set at $33.89 \Omega$ with no time delay, the reach of $Z 2$ is set at

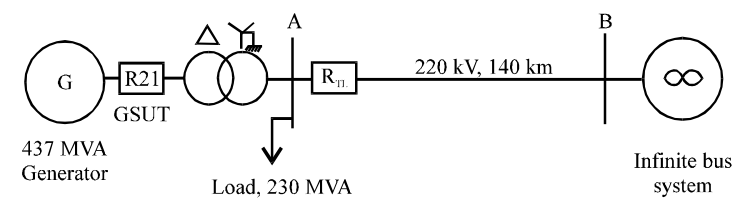

Fig. 5: System model under study

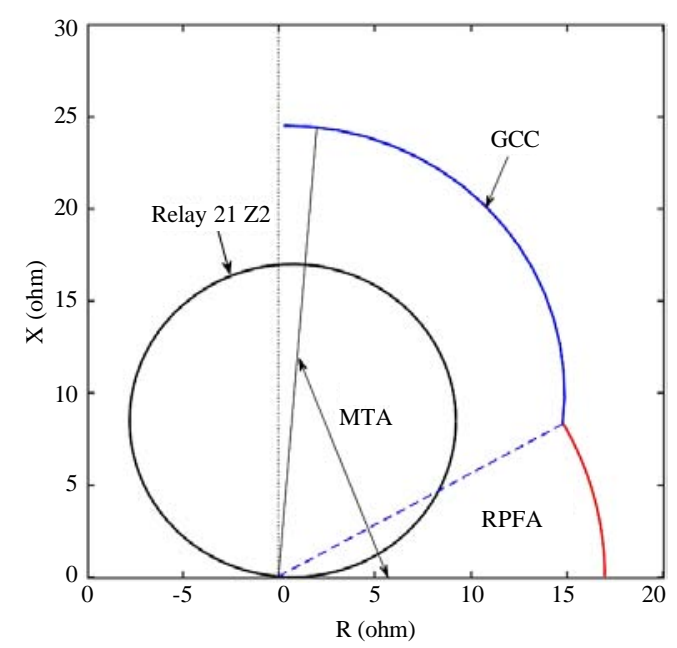

Fig. 6: Impedance characteristics of Relay 21 and GCC on $\mathrm{R}-\mathrm{X}$ diagram 


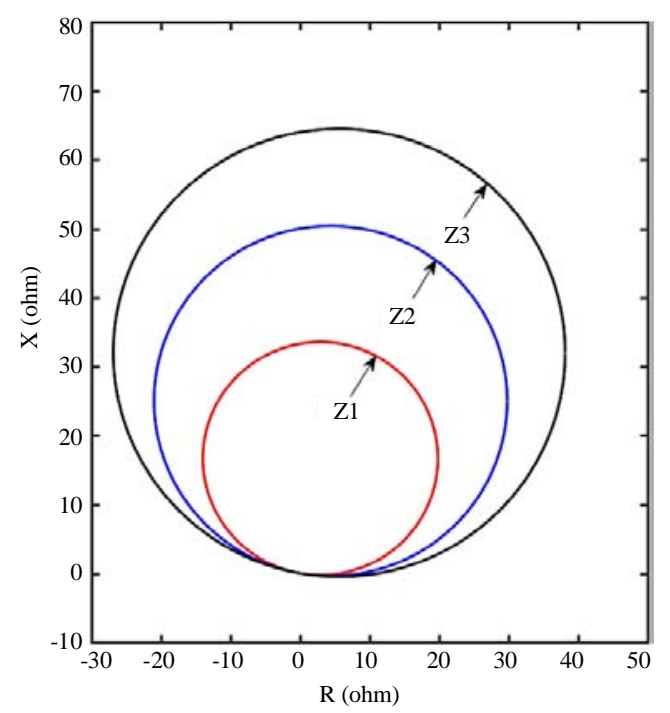

Fig. 7: Impedance characteristics of $\mathrm{R}_{\mathrm{TL}}$

$50.8 \Omega$ with time delay $500 \mathrm{msec}$. and the reach of $Z 3$ is set at $65 \Omega$ with time delay $1 \mathrm{sec}$. Figure 7 shows the reach of these zones using mho type characteristics on the R-X diagram at $\mathrm{MTA}=80^{\circ}$.

\section{RESULTS AND DISCUSSION}

The performance of the proposed scheme is examined during TL HIF illustrated in Table 1, the pre-fault loading condition of the generator in this study is considered at $80 \%$ of its rated MVA as per the recommendation of (WSCC, 2000).

Response of $\mathbf{R}_{\mathrm{TL}}$ during the fault: Figure 8 shows the voltage and current of transmission line during the fault illustrated in Table 1 . In response to small changes of the TL voltage and current due to the fault impedance in addition to the line impedance till the fault point, the apparent impedance seen by $\mathrm{R}_{\mathrm{TL}}$ will be inaccurate. Thus, $\mathrm{R}_{T L}$ will locate the fault at a longer distance location than the actual location of the fault point. Figure 9 shows the impedance trajectory seen by $\mathrm{R}_{\mathrm{TL}}$ during the fault condition. The impedance trajectory penetrates the impedance reach setting of Z3 and stay inside it during the fault; then, Z3 picks up (instead of Z2) and its delay timer $\left(\mathrm{t}_{3}\right)$ starts. After timing out of the timer $\left(\mathrm{t}_{3}\right)$ at $\mathrm{t}=8.83 \mathrm{sec}, \mathrm{R}_{\mathrm{TL}}$ will trip the line and clear the fault.

Response of Relay 21 during and after the fault conditions: Figure 10 shows the generator current and terminal voltage during and after the fault conditions. In response to the changes in the generator current and

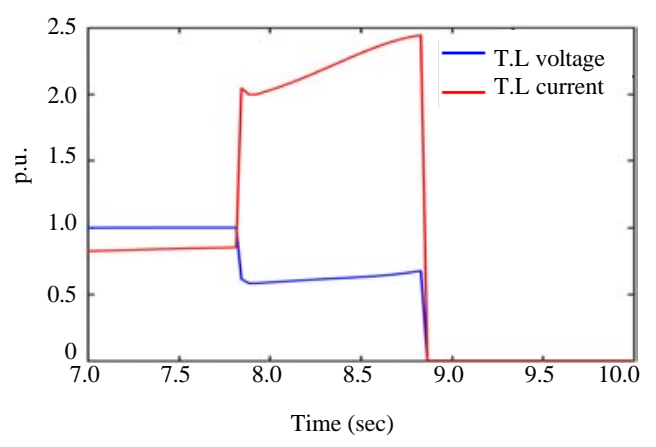

Fig. 8: Transmission line current and voltage during the fault condition

Table 1: The case study of coordinating Relay 21 and $\mathrm{R}_{\mathrm{TL}}$

Generator power and terminal

voltage (pre-fault condition) (p.u) Fault description

$\mathrm{P}=0.8, \mathrm{~V}=1$

A three-phase high impedance fault $125 \mathrm{~km}$ from bus $\mathrm{A}$. Fault impedance $=$ $5 \Omega$, fault inception: $\mathrm{t}=7.83 \mathrm{sec}$

terminal voltage due to the line fault occurred at $\mathrm{t}=7.83$ sec, the impedance trajectory (seen by Relay 21) penetrates the reach setting of Relay 21 Z2 and stays inside it during the fault condition as shown in Fig 11. Thus, Relay 21 Z2 picks up and its timer starts. In order to avoid the unnecessary generator tripping before the line tripping by $\mathrm{R}_{\mathrm{TL}} \mathrm{Z3}$ and thus, maintain the generator connected to the grid as long as $\mathrm{R}_{\mathrm{TL}} \mathrm{Z3}$ is initiated, IEC 61850 -based GOOSE messages are sent from $\mathrm{R}_{\mathrm{TL}}$ to Relay 21 in order to inhibit its tripping action. After tripping the line and clearing the fault by $R_{T L}$ at $t=8.83 \mathrm{sec}$, the changes in generator current and terminal voltage are disappeared and the impedance trajectory seen by Relay 21 jumps outside its impedance reach characteristics and goes out to a new loading point as shown in Fig. 11. Therefore, the generator is maintained connected to supply other loads and support the power system.

GOOSE message published by $R_{\mathrm{TL}}$ during the fault: If a HIF occurs in the T.L and $\mathrm{R}_{\mathrm{TL}} \mathrm{Z3}$ is initiated, it will respond by tripping the line and clearing the fault in defined time delay. Since, it is desired to prevent the unnecessary generator tripping by Relay 21 during the line fault while $\mathrm{R}_{\mathrm{TL}} \mathrm{Z} 3$ sees the fault, the latter will publish a GOOSE message to Relay 21 to inhibit its tripping action. Eventually, $\mathrm{R}_{\mathrm{TL}}$ operates when its timer $\mathrm{t}_{3}$ times out and the fault persists. Figure 12 shows the logic implemented in this research deploying GOOSE.

The above logic can be implemented in the generator protection relay where the pick up signal of $R_{T L} Z 3$ will be 


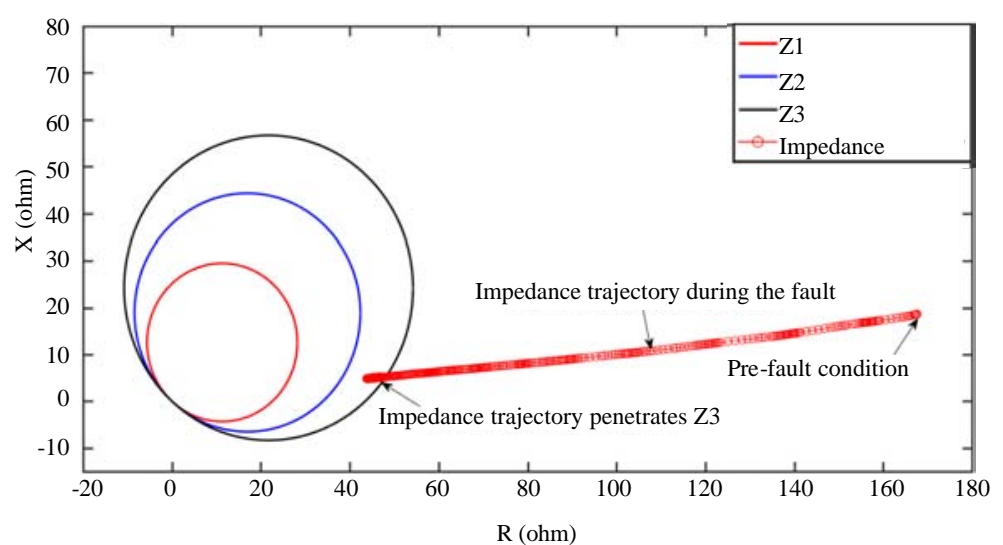

Fig. 9: Impedance trajectory seen by $\mathrm{R}_{\mathrm{TL}}$ during the fault condition

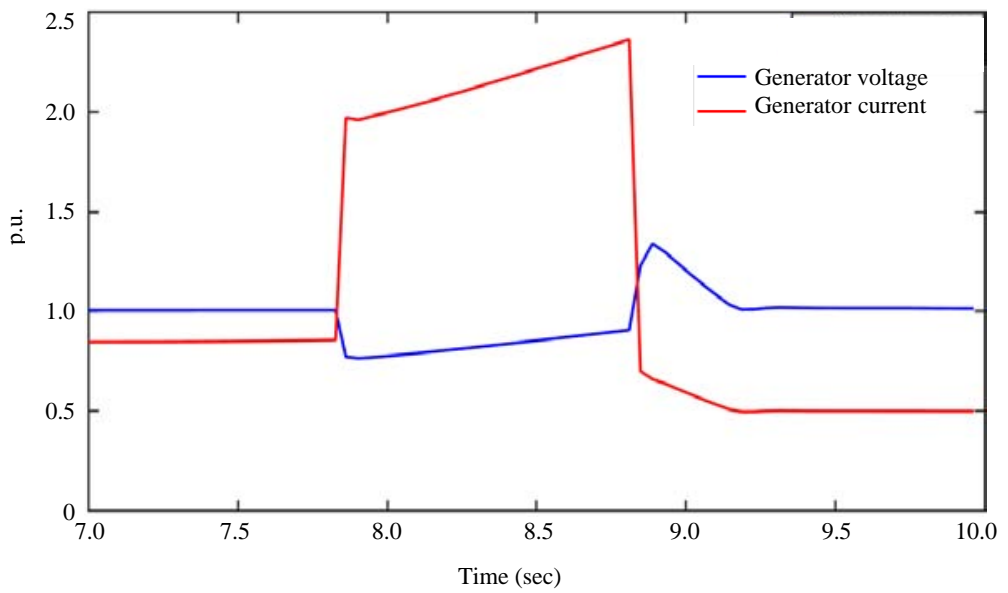

Fig. 10: Generator current and terminal voltage during and after the fault conditions

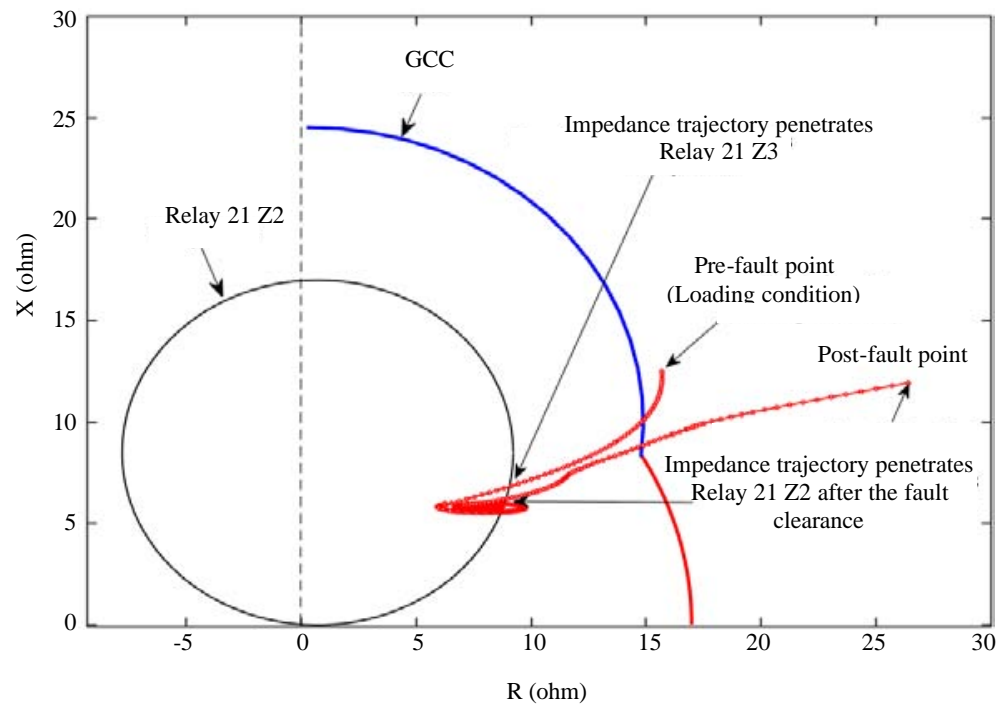

Fig. 11: Impedance trajectory measured by Relay 21 during and after the fault conditions 
received via. GOOSE message. If Relay 21 of the local generator picks up and $\mathrm{R}_{\mathrm{TL}} \mathrm{Z3}$ picks up simultaneously, the logical output (Inhibit Relay 21 Z2 Trip) will be generated. Thus, preventing Relay 21 from tripping during such event. Instead of implementing this logic on the real generator protection Intelligent Electronic Device (IED), it has been implemented on IEC 61850 IED simulator "Xelas Energy Management Simulator". Therefore, the Configured IED Description (CID) file is run on two PCs,

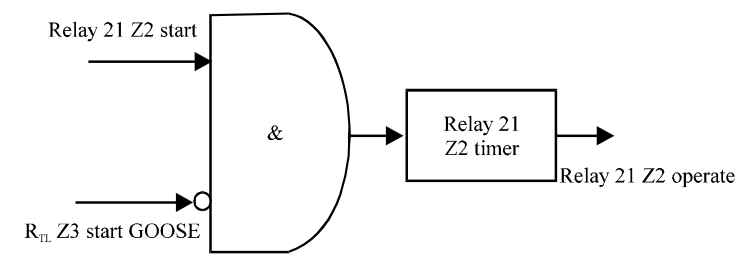

Fig. 12: Logic implemented in the generator protection relay one simulates Relay 21 and the other simulates $\mathrm{R}_{\mathrm{TL}}$. Both PCs are linked via. a direct Ethernet cable. In order to detect the response of the simulated Relay 21, the logical output (Inhibit Relay 21 Z2 Trip) will be mapped to an output GOOSE message via Relay 21 simulator. Both GOOSE messages published by Relay 21 and $R_{T L}$ will be monitored and analyzed by the Wireshark Network Analyzer. This analyzer will run on Relay 21 simulator PC. Figure 13 shows a snapshot of the distance protection CID file running as a server on both machines.

Enabling GOOSE on $\mathbf{R}_{\mathrm{TL}}$ : The proposed scheme utilizes GOOSE messages to convey the Boolean value of the data attribute (EWL03_P442Protection/DisPDIS3.Str.ST. general) of $R_{T L}$ to Relay 21. This attribute as defined by IEC 61850 refers to $R_{T L} Z 3$ general start element value (any of the three phases), either true or false. This indicates whether Z3 picks up or not. Figure 14 shows the start (Str) data object with its attributes.

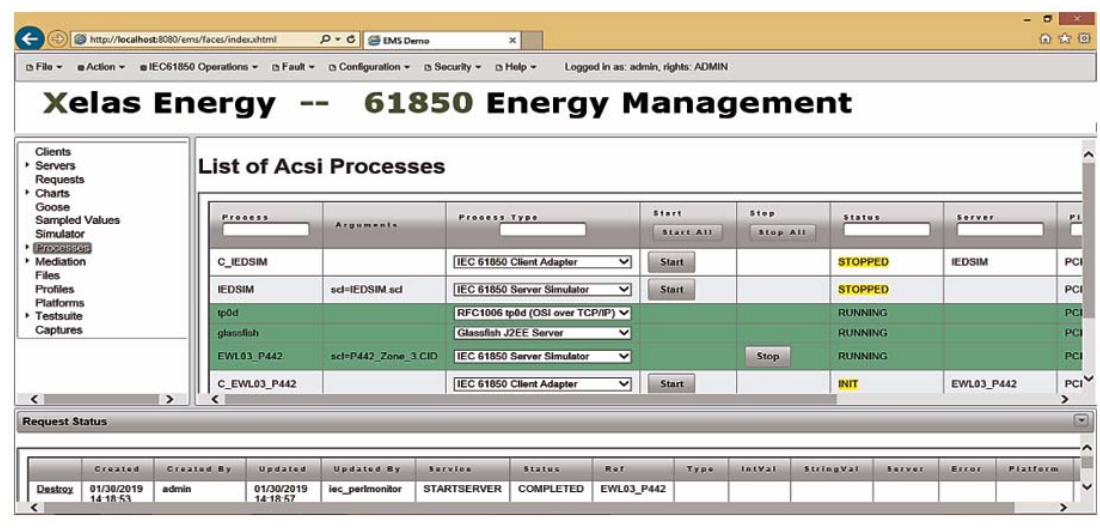

Fig. 13: Distance protection EWL03_P442 server running

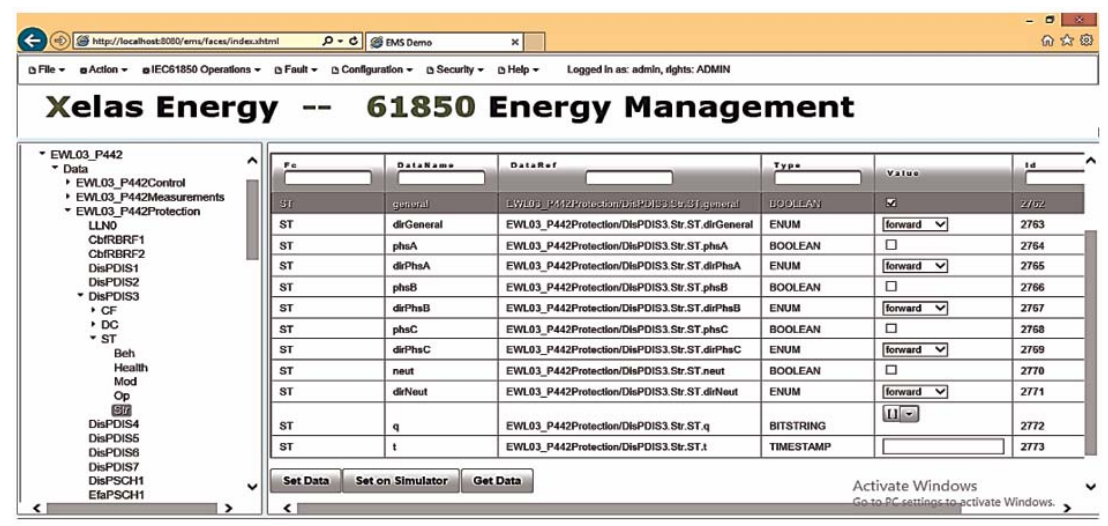

Fig. 14: $\mathrm{R}_{\mathrm{TL}} \mathrm{Z} 3$ start element composition 


\begin{tabular}{|c|c|c|c|c|c|c|c|}
\hline 4 & & & ne Go_gen & er condition9.pcapng & & & $-0 x$ \\
\hline & View Go Copture Analyze Stetistic & phony Wireless & & & & & \\
\hline & (c) I $\triangle \otimes Q Q$ & $\equiv Q Q Q$ & & & & & \\
\hline & 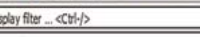 & & & & & & 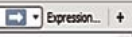 \\
\hline No. & Tine & sarce & Probeced & Desthatoon & Lenght into & & 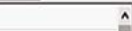 \\
\hline & $12019 \cdot 91-30$ 11:58:53.3710e0 & Dell__b:47:ab & coose & Iec-TC57_01:00:e0 & 174 & & \\
\hline & $220199 \cdot 91-30 \quad 11: 58: 54.379989$ & Dell__b $2 b: 47: a b$ & coose & Iec-TC57_-11:00:06 & 174 & & \\
\hline & $32019 \cdot 91-30$ 11:58:55.370985 & Dell__2b:47:ab & goose & Iec-TC57_e1:00:e0 & 174 & GOOSE packet indicating & \\
\hline & $42019 \cdot 01-3011: 58: 56.371043$ & Dell_ $2 b: 47: a b$ & Goose & Iec-TC57_e1:00:e0 & 174 & $\mathrm{R}_{\mathrm{MI}}$ Zone 3 pickup & \\
\hline & $52219-91-30$ 11:58:57.3792926 & Dell__2b:47:ab & coose & Iec-TC57_-21:00:e日 & 174 & & \\
\hline & $62019-91-30 \quad 11: 58: 58.3779989$ & Dell_ $2 b: 47: a b$ & coose & Iec-TC57_01:00:e0 & 174 & & \\
\hline & $72019-91-30$ 11:58:59.371063 & Oell__2b:47:ab & coose & Iec-TC57_-11:80:e0 & 174 & & \\
\hline & 8 2019-01-30 11:59:00.370945 & Dell__b $2 b: 47: a b$ & coose & Iec-Test_e1:e0:e日 & 174 & $\nabla$ & \\
\hline & $92019.01230111559: 01.203054$ & Dell $2 b: 47: a b$ & cosse & IeC-TC57_11:00:60 & 173 & & \\
\hline & 10 2019.01-30 11:59:01.214768 & Dell_ $2 b: 47: a b$ & coose & Iec-TC57_01:00:e6 & 173 & & \\
\hline & 11 2019-.11-30 11:59:01.245975 & Dell__ $2 b: 47: a b$ & coose & Iec-TC57_-11:00:e0 & 173 & & \\
\hline & 12 2019-01-30 11:59:01.292926 & Dell__b:47:ab & goose & Iec-TC57_01:00:00 & 174 & & \\
\hline & 13 2019-01-30 11:59:01.347113 & Dell_ $66: 68: 16$ & COOSE & Ies-TC57_01:00:09 & 173 & & \\
\hline & 14 2019-01-30 11:59:01.361202 & Dell_66::6:16 & GoOSE & Iec-TC57_01:00:e0 & 173 & & \\
\hline & 15 2019-.11-30 11:59:81.386380 & Dell__ $2 b: 47: a b$ & coose & IeC-TC57_e1: & 174 & GOOSE packet indicating & \\
\hline & 16 2019-81-30 11:59::11.392365 & Dell_-66:c8:1c & coose & IeC-TCST_e1:00:e日 & 173 & Relay 21 Zone 2 operate & \\
\hline & 17 2019-81-30 11:59:01.411597 & Dell_66::8:1c & goose & 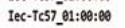 & 173 & Set to false & \\
\hline & 18 2019-.11-30 11:59:01.423665 & Dell- $66: c 8: 1 \mathrm{c}$ & coose & Iec-TC5T_11:00:e0 & 173 & & \\
\hline & 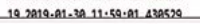 & Aall $65 \cdot 68 \cdot 16$ & soms: & Tec.Tes7 a1:-ab:pa & 133 & & 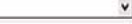 \\
\hline & $\begin{array}{l}173 \text { bytes on wire (1384 bits), } \\
\text { II, Src: Dell12b:47:ab (b8:ac:6 } \\
\text { irtual laN, PRI: } 4 \text {, CFI: } \theta \text {, ID: }\end{array}$ & $\begin{array}{l}\text { es captured (13 } \\
\text { :ab), Ost: Iec- }\end{array}$ & $\begin{array}{l}n \text { interf } \\
: 00 \text { (81: }\end{array}$ & & & & \\
\hline
\end{tabular}

Fig. 15: GOOSE stream capture

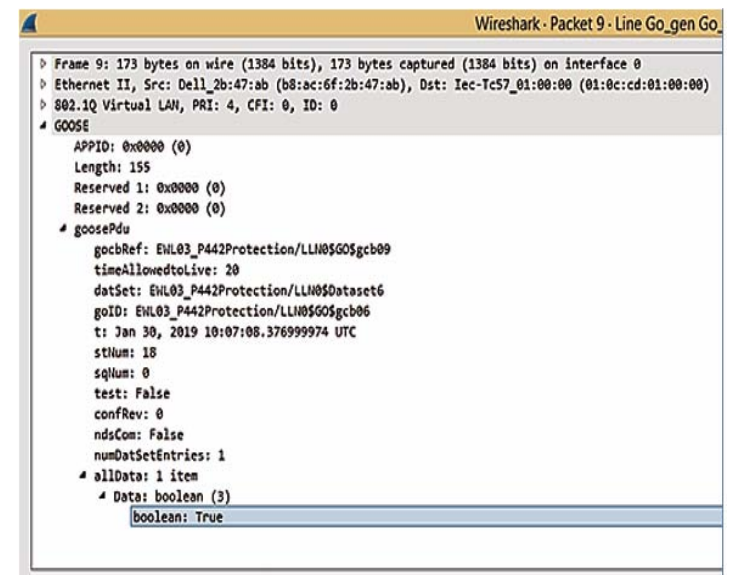

Fig. 16: $\mathrm{R}_{\mathrm{TL}} \mathrm{Z} 3$ picks up

Figure 15 shows the published GOOSE stream where the steady-state transmission $\left(\mathrm{R}_{\mathrm{TL}}\right.$ does not pick up) is displayed in the first eight packets. However, when $R_{T L}$ picks up, a new stream starts from packet No. 9.

According to the logic shown in Fig. 12, if the GOOSE message received by Relay 21 gives true pick up value of $\mathrm{R}_{\mathrm{TL}} \mathrm{Z} 3$ and Relay 21 picks up simultaneously, the latter will be prevented from operation (Data attribute: EWL03_P442 Protection/DisPDIS2.Op.ST. general $=0$ ). This zero attribute value triggers GOOSE stream from Relay 21 starting from packet No. 13 as shown in Fig. 15. A detailed view of GOOSE packets 9 and 13 are shown in Fig. 16 and 17 , respectively.

Using the I/O tool of the Wireshark analyzer, the GOOSE packets versus time graph can be obtained.

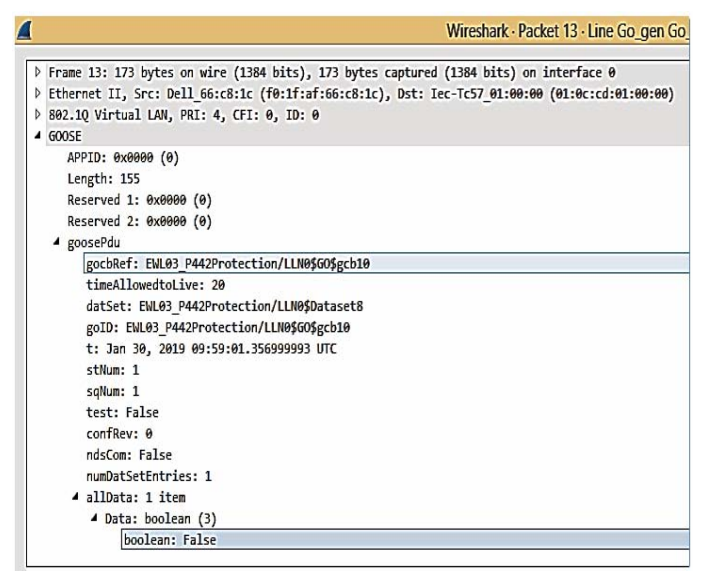

Fig. 17: Relay 21 operation blocked

Figure 18 shows the initiating and triggered packets of $\mathrm{R}_{\mathrm{TL}}$ and Relay 21, respectively. The time span between the two events is about $144 \mathrm{msec}$.

The results obtained in this study show that the proposed IEC 61850-based protection scheme provides accurate coordination of the tripping action between Relay 21 and $\mathrm{R}_{\mathrm{TL}}$ without affecting their main functions in order to maintain the generator connected to the grid during TL HIFs.

Relay 21 is set to provide a backup protection for the generator against TL faults, it may cause trip for the generator during TL HIFs before the faulted line being tripped by $\mathrm{R}_{\mathrm{TL}}$, although, the generator was not at a thermal risk. The proposed scheme helps to prevent the unnecessary generator tripping by Relay 21 during the TL HIFs by using GOOSE communications between 


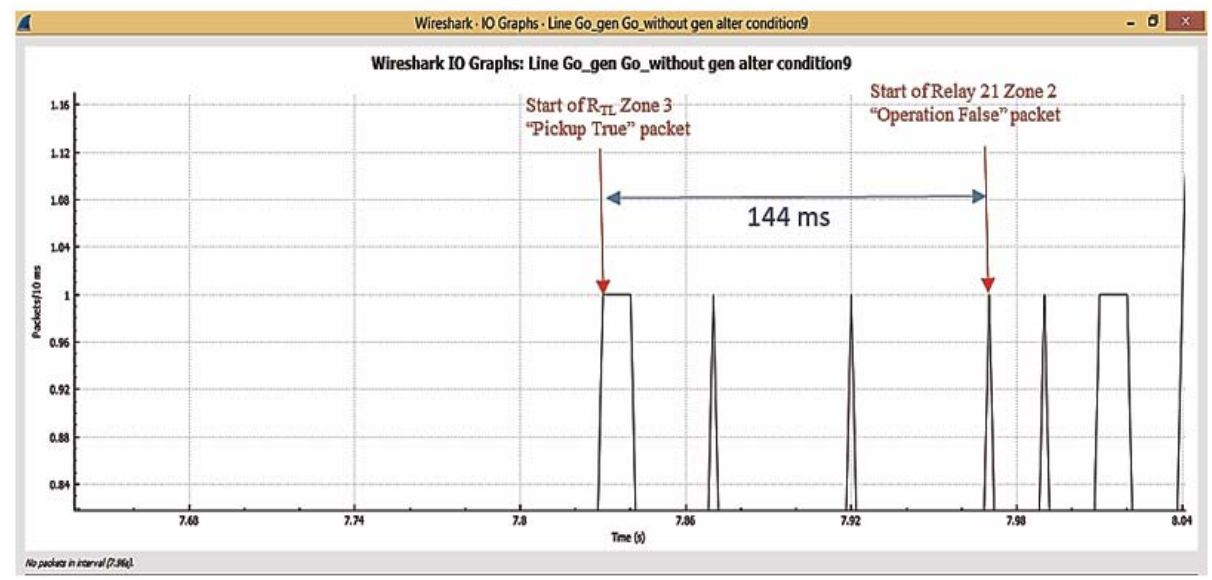

Fig. 18: $\mathrm{R}_{\mathrm{TL}}$ initiating GOOSE and Relay 21 triggered GOOSE packets

Relay 21 and $\mathrm{R}_{\mathrm{TL}}$. When the fault illustrated in Table 1 occurs at $\mathrm{t}=7.83 \mathrm{sec}, \mathrm{R}_{\mathrm{TL}} \mathrm{Z} 3$ and Relay 21 pick up simultaneously and their delay timers start. In the meantime, the pick up status signal of $\mathrm{R}_{\mathrm{TL}} \mathrm{Z} 3$ will be sent via. GOOSE message to Relay 21 in order to inhibit its tripping action till $\mathrm{R}_{\mathrm{T}} \mathrm{Z} 3$ trips the line and clear the fault as shown in Fig. 8-11.

The proposed scheme has been built and applied as shown in Fig. 12-17. Figure 18 shows the initiating and triggered GOOSE packets from $\mathrm{R}_{\mathrm{TL}}$ to Relay 21 during the TL HIF illustrated in Table 1. Relay 21 responds to these GOOSE packets and inhibits its tripping action after $144 \mathrm{msec}$, this interval represents the roundtrip time within Relay 21. According to IEC 61850-5, the total time delay between the $\mathrm{R}_{\mathrm{TL}} \mathrm{Z} 3$ pick up and Relay $21 \mathrm{Z} 2$ trip inhibition can be divided into three intervals: the publishing time of $\mathrm{R}_{\mathrm{TL}}$, the network transfer time from $\mathrm{R}_{\mathrm{TL}}$ and the round trip time within Relay 21 . This can be expressed as:

Where:

$$
t_{\text {total delay }}=t_{a-\text { RTL }}+t_{b}+t_{\text {roundrip }}
$$

$\mathrm{t}_{\mathrm{a} \text { RTL }}=$ The publishing time of $\mathrm{R}_{\mathrm{TL}}$

$\mathrm{t}_{\mathrm{b}}=$ The network transmission time between two relays

$\mathrm{t}_{\text {roundrip }}=$ The time delay between published and subscribed GOOSE within Relay 21

According to IEC $61850-10$, the roundtrip time is defined as shown in Fig. 19:

Where:

$$
\mathrm{t}_{\text {roundtrip }}=\mathrm{t}_{\mathrm{a}}+\mathrm{t}_{\mathrm{c}}+\mathrm{t}_{\text {application }}
$$

$\mathrm{t}_{\mathrm{a}}=$ The publishing time of Relay 21

$t_{c}=$ The subscription time of Relay 21

$\mathrm{t}_{\text {application }}=$ The internal logic processing time of Relay 21

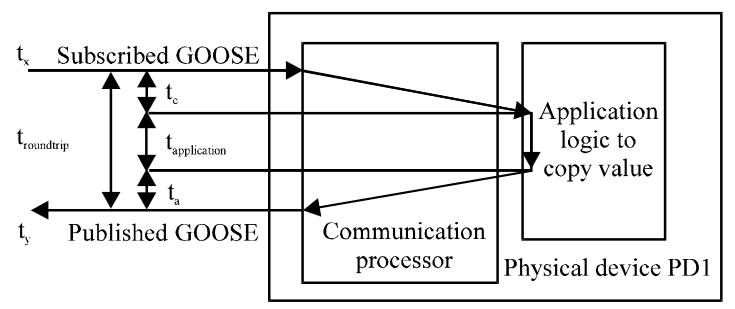

Fig. 19: Ping-Pong method for the round trip time measurement of GOOSE (Schimmel and Xu, 2010)

The publishing time is generally $<1 \mathrm{msec}$ and the network transmission time between two relays is a few microseconds (Schimmel and $\mathrm{Xu}, 2010$ ). Thus, the latter can be neglected and Eq. 1 yields:

$$
\mathrm{t}_{\text {total delay }}=\mathrm{t}_{\mathrm{aRTL}}+\mathrm{t}_{\text {roundrip }}=145 \mathrm{msec} \text { approximately }
$$

This result exhibits a high value whereas the total delay time between real IEDs is in the range of few milliseconds. However, this is due to the long logic processing time $\left(t_{\text {application }}\right)$ in the simulator used in this study. This is an internal issue in the simulator that could be tackled to get it closer to the performance of real IEDs working on Real Time Operating Systems (RTOS).

\section{CONCLUSION}

In this study, the impact of generator distance phase backup protection (Relay 21) on the generator operation during transmission line high impedance faults (TL $\mathrm{HIFs}$ ) has been investigated. The unnecessary tripping of Relay 21 during T.L HIFs has highlighted the 
need for smart coordination between Relay 21 and line distance protection $\left(\mathrm{R}_{\mathrm{TL}}\right)$ to coordinate the tripping action between them during such events. This coordination enables maintaining the generator connected to the grid, thus, allowing the generator to supply the needed support to the system. This research proposes a real IEC 61850-based protection scheme that can be applied to the existing protection relays without any additional cost. The scheme inhibits the generator tripping during HIFs, meanwhile the faulted line is tripped by $\mathrm{R}_{\mathrm{TL}}$. Many simulations have been carried out to investigate the scheme performance which yield satisfactory results that prove the reliability of using this scheme in coordination between Relay 21 and $\mathrm{R}_{\mathrm{TL}}$ during T.L HIFs.

\section{ACKNOWLEDGEMENT}

The researchers would like to thank Eng. Ehab A. El-Metwally, substation communication and protection specialist from PGESCo Company for his contribution and sharing during this research. They would also like to thank Xelas Energy Management for providing the simulator to conduct the research.

\section{APPENDIX}

Network parameters

$220 \mathrm{kV} \pm 10 \%, 50 \mathrm{~Hz} \pm 2.5 \%, 3 \mathrm{PH}$ short circuit current $24.5 \mathrm{kA}$.

Generator data

437 MVA, $21 \mathrm{kV}$, power factor $0.85 \mathrm{lag}, 0.89$ lead, Xd (saturated) $176.6 \%$, X'd (sat) $29.4 \%, X^{\prime \prime} d$ (sat) $18.8 \%, X q$ (sat) $179.4 \%, X^{\prime} q$ (sat) $45.1 \%, X^{\prime \prime} q$ (sat) $19.7 \%, \mathrm{X} 2$ (sat) $19.2 \%, \mathrm{Xo}$ (sat) $10.4 \%$, stator resistance per phase at $20^{\circ} \mathrm{C}(\mathrm{Ra})=0.708 \mathrm{~m} \Omega, \mathrm{J}=8084 \mathrm{kgm}^{2}, \mathrm{H}=0.913 \mathrm{sec}$.

IEEE excitation system model (ST1A)

$\mathrm{T}_{\mathrm{r}}=0.02 \mathrm{sec}, \mathrm{T}_{\mathrm{a}}=0.001 \mathrm{sec}, \mathrm{K}_{\mathrm{a}}=210, \mathrm{VA}_{\min }=-15 \mathrm{pu}, \mathrm{VA}_{\max }=15 \mathrm{p} . \mathrm{u}$, $\mathrm{VR}_{\min }=-6.0$ p.u, $\mathrm{VR}_{\max }=6.43$ p.u, $\mathrm{K}_{\mathrm{F}}=0.001, \mathrm{~K}_{\mathrm{C}}=0.038$ p.u, $\mathrm{T}_{\mathrm{F}}=1$ sec.

Generator distance phase backup protection (Relay 21)

Relay $21 \mathrm{Z} 2\left(\mathrm{Z}_{21}\right)=17 \Omega$ with time delay $=1.1 \mathrm{sec}, \mathrm{Rc}=3000, \mathrm{Rv}=190$, $\mathrm{MTA}=85^{\circ}$.

Generator Step Up Transformer (GSUT) data

$480 \mathrm{MVA}, 21 \mathrm{kV} / 220 \mathrm{kV}, \Delta / \mathrm{Y}_{\mathrm{g}}, \mathrm{X}_{\mathrm{t}}=0.15$ p.u.

Transmission line parameters

$\mathrm{R}_{1}=0.04 \Omega / \mathrm{km}, \mathrm{R}_{\mathrm{o}}=0.25 \Omega / \mathrm{km}, \mathrm{X}_{\mathrm{L}}=0.3 \Omega / \mathrm{km}, \mathrm{C} 1=2.8 \times 10^{8} \Omega / \mathrm{km}$, linelength $=140 \mathrm{~km}$.

Transmission line distance protection Relay $\left(\mathrm{R}_{\mathrm{TL}}\right)$

$\mathrm{Z} 1=33.89 \Omega$ with no time delay. $\mathrm{Z} 2=50.8 \Omega, \mathrm{t}_{2}=500 \mathrm{msec} . \mathrm{Z} 3=65 \Omega$, $\mathrm{t}_{3}=1 \mathrm{sec}$.

$\mathrm{VTR}=220 / 0.1, \mathrm{CTR}=1000 / 5, \mathrm{MTA}=80^{\circ}$

\section{REFERENCES}

Elsamahy, M., S.O. Faried and T.S. Sidhu, 2012. A secure generator distance phase backup protection setting for enhancing generator overexcitation thermal capability during system disturbances. Proceedings of the 2012 IEEE International Conference on Electrical Power and Energy, October 10-12, 2012, IEEE, London, Canada, ISBN:978-1-4673-2081-8, pp: $117-122$.
Fernandes, C., S. Borkar and J. Gohil, 2014. Testing of goose protocol of IEC61850 standard in protection IED. Intl. J. Comput. Appl., 93: 30-35.

Gaur, N., O.P. Mahela and R.N. Mahia, 2015. Impact of power system faults on output power of power plant and power consumption of dynamic loads. Intl. J. Electr. Electron. Eng. Res., 4: 1-10.

Gilany, M.I., B.E. Hasan and O.P. Malik, 2000. The Egyptian electricity authority strategy for distance relay setting: Problems and solutions. Electr. Power Syst. Res., 56: 89-94.

IEC., 2010. IEC 61850-7-2: Communication Networks and Systems for Power Utility Automation-Part 7-2: Basic Information and Communication Structure-Abstract Communication Service Interface ACSI. 2nd Edn., International Electrotechnical Commission (IEC), Geneva, Switzerland, Pages: 218.

IEEE PSRC, 2011. IEEE Tutorial on the Protection of Synchronous Generators. 2nd Edn., IEEE, Piscataway, New Jersey, USA., Pages: 113.

Li, F., Z. Chen, L. Fan and P. Zhang, 2008. Toward a self-healing protection and control system. Proceedings of the 2008 40th International Symposium on North American Power, September 28-30, 2008, IEEE, Calgary, Canada, ISBN:978-1-42444283-6, pp: $1-5$

Mamishev, A.V., B.D. Ussell and C.L. Benner, 1996. Analysis of high impedance faults using fractal techniques. IEEE. Trans. Power Syst., 11: 435-440.

Mozina, C., 2006. Power plant protection and control strategies for blackout avoidance. Proceedings of the 59th Annual International Conference on Protective Relay Engineers, April 4-6, 2006, IEEE, College Station, Texas, USA., ISBN:1-4244-0043-0, pp:1-22.

Mozina, C.J., M. Reichard, Z. Bukhala, S. Conrad and T. Crawley et al., 2007. Coordination of generator protection with generator excitation control and generator capability: Working group J-5 of the rotating machinery subcommittee of the power system relay committee. Proceedings of the IEEE General Meeting on Power Engineering Society, June 24-28, 2007, IEEE, Tampa, Florida, USA., ISBN:1-42441296-X, pp: 1-17.

Patel, S., K. Stephan, M. Bajpai, R. Das and T.J. Domin et al., 2004. Performance of generator protection during major system disturbances. IEEE. Trans. Power Delivery, 19: 1650-1662.

Rani, V.U. and J. Sridevi, 2016. Transmission line protection for symmetrical and unsymmetrical faults using distance relays. Intl. J. Adv. Res. Electr. Electron. Instrum. Eng., 5: 8170-8178. 
Rincon, C. and J. Perez, 2012. Calculating loadability limits of distance relays. Proceedings of the 2012 65th Annual Conference on Protective Relay Engineers, April 2-5, 2012, IEEE, College Station, Texas, ISBN:978-1-4673-1840-2, pp: 1-1.

Schimmel, R. and T. Xu, 2010. Test procedures for GOOSE performance according to IEC 61850-5 and IEC 61850-10. KEMA Nederland B.V., Arnhem, Netherlands. http://testing.ucaiug.org/Testing/ UCAIug\%20Testing\%20Quality\%20Assurance $\% 20$ Program/Current\%20IEC\%2061850\%20Testing\%20 Procedures/Archives(ObsoletedVersions)/Test $\% 20$ procedures $\% 2$ for $\% 20$ GOOSE $\% 20$ Performance $\% 20$ revlp0_14
Tziouvaras, D., 2007. Relay performance during major system disturbances. Proceedings of the 2007 60th Annual Conference on Protective Relay Engineers, March 27-29, 2007, IEEE, College Station, Texas, USA., ISBN: 1-4244-0994-2, pp: 251-270.

WSCC., 2000. Guide lines for over excitation system limiter and over excitation protection testing. Western Systems Coordinating Council (WSCC), Salt Lake City, Utah, USA.

Ziegler, G., 2011. Numerical Distance Protection: Principles and Applications. 4th Edn., Publicis Publishing, Erlangen, Germany, ISBN:978-3-89678-667-9, Pages: 419. 